\title{
The effect of climate change in the future development of tourism: a theoretical approach
}

\author{
G. Galanos \\ Department of International and European Studies, \\ University of Piraeus, Greece
}

\begin{abstract}
Climatic change constitutes a phenomenon which is expected to have enormous impact in the planet as well as in every social and economic sector of human activity. Tourism is an important economic sector, on which the economy of many states is based, as the economic indicators such as the GPD and the employment testify. This research paper constitutes an effort to estimate the effects of the climate change in the tourism sector. The coastal and island touristic regions will face the danger of sea level rise and the increase of temperature. The lack of snow and the extreme meteorological phenomena will place in danger the winter tourism in the mountain areas. impacts will also emerge for a number of touristic resources such as water, the urban environment, the natural and cultural heritage.

The effects of the climatic change will render certain regions less attractive for the tourists and will elect others. The tourism industry has to realize, that it is necessary to proceed in structural changes in order to adapt in the new conditions and simultaneously revise also its attitude towards decreasing the emission of green house gases that intensifies the climatic change. Public authorities are forced to plan investments and take measures in order to prevent or reduce the negative impact of the climate change in the tourist areas.

Keywords: climate change, repercussions, tourism, tourism demand, greenhouse gas emissions.
\end{abstract}

\section{Introduction}

Climatic change constitutes a phenomenon which is expected to have enormous repercussions impact in the planet as well as in every social and economic sector 
of human activity. The effects of the climate changes in tourism would not be of such a crucial matter if tourism hasn't become one of the largest business sectors in the world economy. During the year of 2008 tourism employed more than 200 million people, generated about $\$ 3.6$ trillion of economic activity which represents something between 8 and $12.8 \%$ of jobs worldwide. Reaching 480 million of international tourist arrivals in 2006 and representing the $53.5 \%$ of the world total arrivals (approx. 846 million); Europe is designated as the first destination in the world [1]. The Mediterranean basin covers more than $30 \%$ of international tourist arrivals and is one of the most favourable tourist regions in the world. Out of the world's 25 top tourism destinations in 2006 (evaluated by number of tourist arrivals), 5 destinations are located in the Mediterranean Region (France, Spain, Italy, Greece and Turkey), thus accounting for about $20 \%$ of the total international tourist arrivals in the world [2]. But at the same time tourism is likely to be highly affected by climate change as there many tourist activities depending on weather conditions. In this paper, the following objectives are proposed, a) the research of the impact of the climate change in tourism b) a policy proposal implications for policy makers at different level for the reduction of negative impact of the climate change in the tourist areas.

\section{Description of work and methodology}

In order to meet the objectives of the paper at first a literature review has been carried out. The purpose of this bibliography work was to review and assess the cumulative experience of researchers and practitioners in the area of climate change and tourism, especially to emphasize in studies focusing in the demand and supply of the tourism industry.

This work was followed by a thorough understanding of the factors that are currently affecting tourist activities in a number of specific geographical locations. A number of small scenarios were used for looking in the future and deal with the rising uncertainties. A scenario is the description of a future situation based on present dynamic situation and forecasts. The scenario method was used because it combines isolated ideas about positive and negative changes in individual development factors in the future, in order to form comprehensive pictures and models. Quantitative calculations regarding ecological and financial consequences were beyond the scope of this paper which is focused in finding and illuminating the qualitative analysis of the impacts in human economical and social life and especially those related with Tourism Sector.

\section{Literature review}

Tourism is an industry that depends on the physical environment. Recent research has emphasized the importance of the environment for tourism activity and development and it has also been concerned with the impacts that tourism has on natural resources [3]. During the past few years there have been significant studies on the impact of tourism on the environment [4]. 
Nevertheless, until recently climate change was either considered, more or less, a stable property of destinations that could not account for any long-term trends in tourism demand [5], or was ignored in the literature regarding the impacts of the climate changes $[6,7]$. In recent years there have been several studies focusing on the impacts on the climate change in the tourism industry. More specific, there are studies that investigate the climate impact in single regions [6, $8,9]$ or at a national level $[10,11]$. There also studies that focus on destination types such as ski areas, parks and coastal zones $[12,13]$, or others that are focusing on the effects of the climate change on an international level $[14,15]$. Most of these studies have used econometric models in order to examine either the demand or the supply in the tourism industry. Regarding the demand, there were a lot of studies focusing on the sensitivity of destinations choices by the international tourists to climate [16-18]. All these studies came to the conclusion that the climate is an important consideration for tourist choice of destination and a "gradual warming would induce tourists to seek different holiday destinations or travel at different times during the year." Hamilton et al. [15] have developed an econometric simulation model of the travel patterns of tourist which has been called "Hamburg Tourism Model (HTM)" and they have found that "climate changes affects international tourism but this effect is small compared to other changes in the industry". Also, in a latter application of the HTM model [15] they have estimated that "climate change would lead to a gradual shift of tourist destinations towards the poles and up the mountains". The work of Hamilton was further refined [8] and they have concluded among other things that the global warming which is caused by the climate changes will affect the international tourism destinations by changes in the strength of the pull effect of the home country, tourists from warm places will spent their holiday in their home countries and not abroad.

Within studies, various authors have looked at the potential impact of the climate change on the supply in the tourism industry [7] and have studied the potential changes in the spatial and temporal distribution of the climate resource for tourism in North America. With the use of Tourism climate index of Mieczkowski model they have concluded that climate changes will affect the supply capacity of specific regions and eventually reduce tourist demand. Muller and Weber [19] have studied the impact of climate change on tourism on regional level in the area of Berness Oblerland. With the use of scenario methods they came to the conclusion that tourism product of the examined area will be highly affected by the climate change and perhaps will destroy the bases of tourism industry on the area. The same results came out from the research of Elsasser and Bürki [10] which they also predicted that the impacts of climate change will involve significant costs for tourism in Switzerland. One other approach was made by Hein et al. [11], in their research with the use of spatial variations in climate change, linking physical and economic impacts and modelling societal changes in the attractiveness of the climate for tourism at the European scale they have confirmed the Hamilton et al. [15] findings that the climate change will effect both destination and source countries. 
The most important studies in the field were made by the recent report "Climate change and tourism - Responding to global challenges" published by the United Nations World Tourism Organization (UNWTO) [20] and the United Nations Environmental Program (UNEP), and the "Climate Change Adaptation and Mitigation in the Tourism Sector: Frameworks, Tools and Practices (2008) also by the United Nations World Tourism Organization (UNWTO) and the United Nations Environmental Program (UNEP) [21]. Both these studies are analyzing the interrelationship between climate change and tourism focusing at the main impacts and to providing guidance to tourism stakeholders to integrate sustainability into their decision making processes and operations.

\section{A review of effects of climate change in tourism areas}

In climate change, the tourism industry is now confronted by a new challenge. Unlike natural disasters or terrorist attacks, this is not just a short-term effect that could then be quickly forgotten. Rather, climate change will permanently alter the attraction of some holiday regions and force them to take steps to adapt in the next few decades. It is taken for granted that there will be regional and seasonal shifts in both national and international tourist flows during the next few years.

\subsection{Climate change effects on coastal areas}

In the scientific literature the forthcoming rising of sea level is reported as one of the major impacts of climate change. Global mean temperature rising due to greenhouse emissions effect will result in melting of poles ice, which will lead to the rising of the sea level. Certain studies, taking advantage of sophisticated measuring tools such as GIS systems and satellite image and spectroscopy data, are indicating that it is possible for the sea level to rise about $50 \mathrm{~cm}$ in the next 50 years. Even though this figure might not seem devastating it will be however a disaster for coastal regions and regions already below sea level like Low Countries [21].

Tsunami hit in Maldives islands complex revealed the size of damage which can be done to infrastructure and ordinary living when a low altitude region comes across sea level rising. Of course this phenomenon was not originated from global warming effect, but from an ordinary earth activity like earthquakes. Nevertheless it offered us a clear image of the tide corner these regions are going to come on the years to follow. It must be noted however that other islands in the same regions came across of high waves originating from vast storms and tidal phenomena, which are related to global warming. Incidents like these can injure irreparably the economy of islands like Maldives, which is totally based on income from tourism. Of course we have to stress here that a $50 \mathrm{~cm}$ rise of sea level will not result only in affecting Maldives's economy but is going to lead this small insular country to extinction.

It is well beyond doubt that these phenomena will not occur only in tropical regions but will expand to the global. For example it is estimated that if temperature raises $4^{\circ} \mathrm{C}$ the one fifth of the whole planet will come across with 
flooding phenomena. In this framework there is a lot of conversation in Italy about the measures which have to been taken for preventing the permanent flooding of the city of Venetia. It is well known the importance of this city to the whole building of the Italian touristic economy. A future without the presence of this city on the touristic map of Italy is a casualty that the country cannot stand. So an expenditure of about 5 billion Euros is allocated in order to save the historical centre of the city from becoming an underwater sightseeing in the next few decades.

The consequences of climate change and global warming are expected to be more obvious and critical in the coastal and insular areas. Beyond the effect of losing in the future areas that today are solid ground, the tight economical link of these areas with sea related activities makes the whole change effect more intense. The touristic sector is expected to suffer serious threats and obstacles. More specific the predicted sea level rise will lead in eroded coastlines, massive floods, extinguishment of coastal ecosystems, and finally in the vanish of a number of islands. Even though this latter result might bring in mind the Atlantis myth, scientists insist that this is a part of the future to come.

Another side effect of the global warming is that just like the way air temperature rises, so will sea temperature. Rising of sea temperature is expected to trigger the birth of hurricanes in regions where this phenomenon is almost unknown until present. More specific streams of cold air will come in contact with hot water streams during summer time resulting in the appearance of occluded front which finally leads to hurricanes formulation. These phenomena might be very common in tropical areas, but in the future are expected to make their appearance in non-tropical areas like the Mediterranean Basin. Hurricanes season does not coincide with the touristic peek session, but it is easy to realize the extent of the infrastructures which are going to be touched by these enormous storms.

It is easy to imagine that exactly like the way natural and human life is affected in mainland so is sea life. For example reefs and their rich ecosystems are facing a deadly threat since they appear one of the most sensitive but also profitable for tourist sector type of ecosystems. Their unique flora and fauna appears to be more than important for the tropical areas they are located to, but so it is the threat their facing. However all sea regions are expected to be affected. The recent appearance of the poisonous fish "Lagocephalus" in the Mediterranean Sea, originally living in tropical seas, is one of the most known example but not the only one.

\subsection{The reefs case}

In the tropical regions scientists are already started to log down the first victims of climate change effect and the phenomena that come as a result of it, such as temperature rise both in air and water. As we mentioned before reefs and the ecosystems they are supporting due to their uniqueness and beauty are worthless both from ecological and financial view. A vast portion of visitors in tropical and 
subtropical regions are attracted from their wealth of life, colours, shapes and sightseeing. It is easy to conclude that reef's evanescence results in the shrinkage of visitors flow to. The Caribbean Islands case is indicative, where since 2005 reef's region has been reduced to one half. It is estimated that due to an average rise of just $1 \mathrm{oC}$ in sea water resulted in vanishing a large portion of Australia's reef regions. Taking under consideration the number of businesses, activities, and work labour these regions supported it is easy to estimate the damage that touristic industry is suffering there.

United Nations have stressed these issues and its specialized branch, United Nations Environment Programme (UNEP) together with countries like, United States of America, Australia and France have taken specific measures trying not only to stop reef's decay but if possible to reverse the trend. Disasters like Katrina Hurricane in New Orleans [20] demonstrate the impact of global warming in human activities, and the loss of money, resources and above all human lives that they can cause. Scientists point to Climate Change for the cause behind the increasing number and destructiveness of hurricanes in tropical and subtropical regions.

Finally in the overall consequences from reef's areas shrinkage it has also to be taken into account the damage done to fishing industry. Reefs are supporting a large variety of sea life, expanding well beyond their very geographical boundaries, keeping a critical role in safeguarding food chain supporting indirectly creatures living either in or outside the reefs. It cannot be ignored that, humans, are standing on the edge of this chain and a change in the begging of it cannot but affects everybody.

\subsection{The Mediterranean case}

Mediterranean Sea consists one of the most important touristic worldwide destinations. Visitors rise to the number of about 120 millions annually. Its attractiveness lies in the diptych "Sun-Sea" where spectacular shores are combined with mild weather. Beyond the obvious benefits for European Union's economy as a whole, there is also a cash flow generated, from the wealthier northern European countries to the southern European ones.

An increase of mean temperature in European Continent will cause several side effects. It is possible to transform south Europe from a friendly, mildly warm place to an extremely hot region with potential dangerous sun radiation. Heat waves are expected to become more common, severe, and standing. Further raining decimation is a likely possibility which is expected to result in an even more dramatic decrease in water reserves. All the above will lead to an inhospitable place, especially for the weakest ones, like children and elders. Water supply will be more problematic than today, and a questions rises for the capability of a number of islands to support even their native population. To face this problem large investments and infrastructure is demanded, however taking under serious consideration various and complex environmental issues.

Together with the gradual decay of the southern tourist destinations, temperature rise is expected to transform in the same time northern destinations 
into very attractive and friendly regions for summer vacations. It is expected that regions in the northern part of Mediterranean Basin will gain more tourist attention when southern regions will strangle to keep up [22]. But also on the same time another side effect is expected to make its appearance. Many analysts suggest that since the weather will become warmer in a large area of Central and Northern Europe their habitants will not be so eager to leave their homeland and the present tourist stream might severely weaken [23].

\subsection{Greek coastal regions and islands case}

Greece, with its coastal and island region, stands for a typical Mediterranean terrain mosaic. Greek mainland is surrounded by more than two thousands smaller or bigger islands, some of them having rich forests and plenty of water supplies but with others having hardly some of this vital resource. The total coastline of Greece spreads for more than sixteen thousands kilometres. More than seventy percent of its population is living in establishments nearby the sea, giving us a clear indication about the tight link between its people and the sea.

The effect of climate change was not obvious in Greece until recently. Mean temperature appeared a negative trend until 1975, but after then it is continually rising. Some rather extreme phenomena are making their presence in a more systematic way ever since. 1989-90 was the most anhydrous period the country faced in its recent history resulting in serious decay of the available water supplies. 2007 was also characterized as the warmer year respectively. The highest temperature for this year was measured at $44,8^{\circ} \mathrm{C}$ when the average temperature for the whole summer period was $34,9^{\circ} \mathrm{C}$. The following winter was also the most anhydrous winter measured the last 100 years. Month January was also the second warmer for the same period of time. Finally sea level is constantly raising 1-2mm per annum. [24]

For the next half century Greece is following the global trend and an increase in mean temperature is expected. As a result an increase in the duration of the summer session is also forecasted as well as to the maximum temperatures. These weather conditions are going to create conditions hardly affordable, a clue which is going to have seriously negative implications on the Greek tourism industry.

As it was mentioned before, one of the major threats that Greece is facing is the forthcoming unbalance of the water cycle, and the resulting water supplies deficit. This situation will highly likely to lead in dryness of the earth and desertification of vast areas of Greek soil. This is a highly possible scenario for many of the Greek islands which are already facing serious desertification problems due to lack of fresh water.

Since tourism industry in coastal and island areas cannot prevent climate change by itself, it has no other chance but to try to preserve and maintain the natural resources available, plan carefully for the future and strongly contribute to the global effort of minimizing global warming gas emissions. Taking measures for protecting coastal areas from flooding and erosion, reserving water supplies and re-engineering touristic development strategies can safeguard the future of the sector as well as the welfare in these regions. 


\subsection{The effect of global warming in mountainous areas}

Global warming does not affect as it is easy for someone to suspect only coastal areas but also mountainous ones. There are two aspects in the study of this problem. The first has to deal with the consequences in natural capital and the second with the impact on human activities and especially winter tourism.

Two are the main problems mountainous areas are facing due to climate change. The first has to do with the water cycle and the resulting decrease of the water arriving in these areas either in rain or snow form. These result in turning mountainous forests more flammable due to lack of moisture, raising the possibility of forestry fires and jogging subsequently desertification effects. These phenomena intensify the water cycle unbalance accelerating the whole effect. However climate forecasting indicates that at the same time storms of extreme intension are going to be more usual.

A wide range of human activities are depending in mountainous flora and fauna. This includes both fostering and animal farming. Additionally a wide range of tourism activities is formulated during the last decades. It is a fact the establishment of novel business initiatives mainly dealing with alternative forms of tourism. New tourism strategies must be developed since it becomes clearer every day that wild life is struggling against livelihood and tourist human activities in an everlasting shrinking mountainous natural environment.

Nevertheless tourism sector activities in mountainous areas are devastated by winter skiing. Global warming however constitutes a serious threat for winter skiing since these areas proved to be more sensitive. It is characteristic that during last century, temperature rises in poles two times faster than in the rest of the world. Also it is more than evident that snowfalls and areas covered by snow are constantly decreasing. During winter of 2006-07 Canada's winter tourism industry faced serious operating problems due to the lack of snowfalls. Several other countries which have large scale winter tourism facilities are facing the same kind of problems.

A large proportion of the central European population is totally dependent upon winter tourism activities, and global warming consists for countries like Switzerland a major threat for their financial surviving [25]. To make this even clearer eighty five percent of Switzerland's tourist establishments are totally depended upon winter sports [10].

According to scientific forecasts the altitude upon which snow cover is suitable for skiing activities for more than one hundreds days per annum is expected to rise in the next few years from the present $1200 \mathrm{~m}$ to $1800 \mathrm{~m}$. Under this scenario $44 \%$ of the tourist establishments in the Alps are expected to face serious operating problems. Going back to Switzerland case it is estimated that climate change will cost annually to the country approximately 1,7 million dollars, which equals to the $0,7 \%$ of its annual domestic product.

It is very well documented that noticeable spatial distribution is expected to occur in the next decades regarding winter tourism activities and especially as long as it concerns winter skiing. Milder winder temperatures together with 
outbreaks of storms of great intense are expected to cause serious obstacles in mountainous tourism enterprises and establishments.

\section{Suggestions for the future of tourist development}

As it has already been referred in this paper the effects of the climate change in the tourism industry will be enormous. Tourism industry has to adobe a great number of measures in order to face the future (Tourism Review). First of all, citizens and professionals of tourist destination have to get aware for the real dimensions of the problem. Only if it becomes comprehensible the problem and the likely impacts of this, can advance the planning for its confrontation. Until today, scientific community reports that maybe we haven't experienced the full impact of climatic change. As long as irresponsible human activity is continued and no essential measures are taken for the restriction of emissions of greenhouse gases, the change of climatic conditions will be continued with continually growing intensity. For the convenient forecast of repercussions of climatic change, for the protection of installations and infrastructures of tourism and for the protection of tourist's and resident's life, it is considered necessary the creation of institution of follow-up of climatic changes. Such an institution that will practice its duties under the aegis of international organisms might constitute a useful tool for the branch of tourism.

The establishment of a tourist enterprise requires in most cases a certain global procedure with a number of legal documents according to the state law. In the past few years, particular attention was given in the protection of environment so much at the duration of manufacturing the enterprise, mainly however during its operation. The change in climatic conditions however and the repercussions of this, give birth also to the need for incorporation in the process of awarding, of vacations, of new investments and in the scientific forecasts that concern the consequences of climatic changes. As an example in the coastal and island regions where tourist activity is developed it will be supposed they will be taken into account and the meteorological phenomena which will make their appearance.

Finally some additional measures which will assist this effort include the encouragement of innovation and diversification, the reinforcement of hazard prevention and the modern organization management for taking suitable technical measures resulting in risk reduction.

\section{Conclusions}

The analysis of this paper leads to the conclusion that climate change and tourism are definitely strongly linked and in order to maintain their "market value" touristic destinations and enterprises ought to adapt in the new reality that is imposed by climate change. This change of weather conditions is not something that is going to happen in the future in certain areas but something that is happening today globally. The whole planet is going to be affected by climate change and especially the tourism destinations. For the global tourism 
industry, climate change brings more risks than opportunities. There will be regional and seasonal shifts in tourist flows, resulting in both winners and losers. However, it is undoubted that the tourism industry will continue to be a growth sector, despite the challenge of climate change. In Europe, countries bordering Mediterranean Sea will particularly suffer from climate change. Higher temperatures and water shortages could put off tourists in high season. This is particularly true for countries in the eastern Mediterranean. In contrast, those that could gain profits from this forthcoming reality are: the Benelux countries, Denmark, Germany, and the Baltic countries. France and Italy will be slightly favoured, due to the diversified structure of their tourism offers. Outside Europe, most countries will suffer from climate change, albeit to differing degrees. Especially for the poorer countries in our investigation, which are putting great hopes on tourism as a driver of development, climate change will principally bring additional burdens.

Tourism industry has to protect its product from climate change and also has to re-define its policies that until now have contributed to the inflation of the problem. Tourism sector has to take all the necessary measures for the protection of the tourism development areas. Coastal areas should take under consideration for example the new practices for the management of water resources and also make investments for facing the raise of sea level.

Mountainous areas have to protect their forest regions and the ecosystems surrounding them. Winter tourism destinations such as for example Alps will face significant problems caused by the lack of snow or even by the powerful storms. The adaptation of tourist industry in this new data will decrease the dangers and will allow the further development of tourism areas. The causes of climatic change are mostly the result of human activities on the entire planet. The direct repercussions of climatic change however will concern the local level and so it is very difficult for a local community or even a single state to bear the weight of crisis. The need of a different way for the development of tourism has to be one of the most important discussions not only within the tourist industry but for the worldwide economic sectors.

Tourism industry has to impose and also develop a leading role for the confrontation of climatic changes. From one part has to find the way in order to develop its activities taking into consideration the dangers and the threats that be born from the climatic change and also has to try as much as possible to minimize his own contribution in this. Even thought the forecasts of international organisms and scientific community, for the severity of repercussions of climatic change in the natural and human environment, are pessimistic, it is possible, with the suitable investments and with the change of mentality, to protect the natural resources and also to reduce the effects of climate change.

This paper emphasized in the importance of a new set of sustainable development strategies that can be used from the tourist industry for the incorporation of climatic change in its developmental planning and the protection of tourist product, the viability of its enterprises and income and work of millions of workers. As it has been formulated in this text, the shock of tourist 
branch is expected to have side effects, almost in every part of world's economy chain.

\section{References}

[1] UNWTO, World Tourism Barometer, www.unwto.org, 2008.

[2] UNWTO, Tourism Market Trends, www.unwto.org, 2008

[3] Green H., Hunter C. \& Moore B. Assessing the environmental impact of tourism development-- use of the Delphi technique, Tourism Management, 11, pp. 111-120, 1990.

[4] Goessling S, Glibal environment consequences of tourism, Global Environ Change 12:283-302, 2002.

[5] Abegg B., Koenig U., Bürki, R and Elsasser H., Climate impact assesment im Tourismus, Die Erde 128 pp. 106-116 1997.

[6] Smith J.B., Schellnhuber H.J. and. Mirza M.M.Q, Vulnerability to Climate Change and Reasons for Concern: A Synthesis., Chapter 19 in Climate Change: Impacts, Adaptation, and Vulnerability, J. McCarthy, O. Canziana, N. Leary, D. Dokken, and K. White (eds.). Contribution of Working Group II to the Third Assessment Report of the Intergovernmental Panel on Climate Change. Cambridge University Press, Cambridge, UK. pp 913-967 2001.

[7] Scott, D, McBoyle G., Schwarzentruber M., Climate change and the distribution of climatic resources for tourism in North America, Climate Research, 27, 105-117, 2004.

[8] Hamilton J.M. and. Tol R.S.J, The impact of climate change on tourism in Germany, the UK and Ireland: a simulation study, Regional Environmental Change 7, pp. 161-172, 2007.

[9] Moreno A. and Amelung B., Climate change and tourist comfort on Europe's beaches in summer: a reassessment, Coastal Management 37, pp. 550-568, 2009.

[10] Elsasser H. and Bürki R., Climate change as a threat to tourism in the Alps, Climate Research Vol. 20:pp 253-257, 2002

[11] Hein L., Metzger M.J and Moreno, A Potential impacts of climate change on tourism; a case study for Spain. Current Opinion in Environmental Sustainability Volume 1, Issue 2, December 2009, pp 170-178, 2009.

[12] OECD, Climate Change in the European Alps: Adapting Winter Tourism and Natural Hazards Management, Organisation for Economic Cooperation and Development, Paris, 2007.

[13] Jones B. and Scott D., Climate change, seasonality and visitation to Canadás National Parks, Journal of Parks and Recreation Administration 24, pp. 42-62, 2006.

[14] Nicholls S., Climate Change and Tourism, Annals of Tourism Research, Vol. 31, No. 1, pp. 238-240, 2004.

[15] Hamilton J.M., Maddison D.J., Richard S. J. Effects of climate change on international tourism. Climate Research Vol. 29: pp 245-254, 2005. 
[16] Syriopoulos, T. C. and Sinclair M. T., An Econometric Study of Tourism Demand: The AIDS Model of U.S. and European Tourism in Mediterranean Countries', Applied Economics 25, 1541- 1552, 1993.

[17] Witt, S. F. and Witt, C. A., Forecasting Tourism Demand: A Review of Empirical Research', Int. J. Forecasting 11, 447-475, 1995.

[18] Wietze L. and Tol R.S.J. Impact of Climate on Tourist Demand, Climate Change 55: pp 429-449, 2002.

[19] Muller H. and Weber F., Climate change and tourism - scenario analysis for the Bernese Oberland in 2030, Tourism Review vol. 63 no. 3 pp. 57-71, 2008.

[20] Scott D., Amelung B., Becken S., Ceron J.P., Dubois G., Gossling S., Peeters P and Simpson M.C.,. Climate Change and Tourism-Responding to Global Challenges, United Nations World Tourism Organization, Madrid, 2008

[21] Simpson, M.C., Gössling, S., Scott, D., Hall, C.M. and Gladin, E., Climate Change Adaptation and Mitigation in the Tourism Sector: Frameworks, Tools and Practices. UNEP, University of Oxford, UNWTO, WMO: Paris, France, 2008.

[22] Carter, G. A., Primary and secondary effects of water concentration on the spectral reflectance of leaves. American Journal of Botany, 78, pp916- 924, 1991.

[23] Perry A. (, 'Impact of climate Change on Tourism in the Mediterranean: Adaptive Responses, Nota di Lavoro, 35, Bergamo 2000

[24] Gouta L. Climate Changes - Worldwide problem Conference for the energy and the environment, Thessaloniki 30-11-2007, available on http:/www.lianagouta.gr/website/pdf articles/250920081450.pdf

[25] Bigano A., Jacqueline M.H. and Tol R., 'The Impact of Climate Change on Domestic and International Tourism: A Simulation Study', Notta di Lavoro, Vol. 86 Bergamo Tourism Management 27, 913-924, 2006. 